\title{
Ultrastructural complexity of nuclear components during early apoptotic phases in breast cancer cells
}

\author{
Christian Castelli a and Gabriele A. Losa ${ }^{\text {a,b,* }}$ \\ ${ }^{\text {a }}$ Laboratorio di Patologia Cellulare, Istituto \\ Cantonale di Patologia, Locarno, Switzerland \\ ${ }^{\mathrm{b}}$ Istituto di Studi Scientifici Interdisciplinari, Locarno, \\ Switzerland
}

Received 31 January 2001

Accepted 19 April 2001

Fractal morphometry was used to investigate the ultrastructural features of the plasma membrane, perinuclear membrane and nuclear chromatin in SK-BR-3 human breast cancer cells undergoing apoptosis. Cells were incubated with $1 \mu \mathrm{M}$ calcimycin (A23187) for $24 \mathrm{~h}$. Cells in the early stage of apoptosis had fractal dimension (FD) values indicating that their plasma membranes were less rough (lower FD) than those of control cells, while their perinuclear membranes were unaffected. Changes of the chromatin texture within the entire nucleus and in selected nuclear domains were more pronounced in treated cells. This confirms that the morphological reorganization imputable to a loss of structural complexity (reduced FD) occurs in the early stage of apoptosis, is accompanied by the inhibition of distinct enzymatic events and precedes the onset of conventional cellular markers, which can only be detected during the active phases of the apoptotic process.

Keywords: Apoptosis, breast cancer cells, electron microscopy, fractal dimension, gray level tresholding segmentation, nuclear chromatin, flow cytometry, acidic sphingomyelinase, $\gamma$-glutamyltransferase

\section{Introduction}

Apoptosis is a physiological form of cell death that occurs in all tissues and in which cells committed to die

\footnotetext{
${ }^{*}$ Corresponding author: Gabriele A. Losa, Laboratorio di Patologia Cellulare, Istituto Cantonale di Patologia, v. in Selva 24, 6600 Locarno 1, Switzerland. Tel.: +41 91 7562680; Fax: +41 91 7562691; E-mail: glosa@guest.cscs.ch.
}

undergo a series of characteristic functional and morphological changes that are mostly irreversible [1-4]. It is rather difficult to recognize and quantify apoptosis in solid tissues because it is relatively rapid in vivo and because apoptotic cells are efficiently removed from a tissue by phagocytosis. While measurable apoptosis may be relatively rare in living tissues because this is a natural residual process [5,6], the methods currently available do not adequately identify the early phases of apoptosis when the cells appear overtly normal and healthy. It is not even easy to recognize the early phases of apoptosis experimentally induced in cultures of epithelial and other non-lymphoid cells by either visual inspection of morphological features or biochemical measurements of functional markers because these become evident only during the active or late phases of apoptosis. However, fine ultrastructural changes may occur in the plasma and nuclear membranes or in other organelles and in nuclear chromatin at the beginning of apoptosis. They could be evaluated using unconventional methods of morphometry, based on fractal geometry [7]. This implies that the mostly irregular cell and nuclear components need not to undergo reductive representations and/or unrealistic approximations in order to be analyzed, as is usual in conventional morphometry when a single arbitrary scale is used to measure a large number of morphological features [8]. The irregularity and roughness of cell membranes and nuclear components (morphoultrastructural complexity) can be quantified by a single descriptive parameter, the fractal dimension (FD), while the true length contour and the actual surface area of biological bodies are obtained at the most suitable resolution scale [9-12]. Several reports have documented the use of fractal morphometry for describing irregular morphological traits and changes in the ultrastructural features of membrane organelles, including chromatin and other nuclear components in various types of healthy, pathological and/or tumor cells. The fractal approach can also be used to evaluate morphohistological traits for objec- 
tive diagnosis [13-20]. The reliability of ultrastructural fractal methods has been assessed by quantifying the early effects of steroid hormones on the nuclear heterochromatin organization of breast cancer cells [21]. The present study evaluates the changes in the ultrastructural morphology occurring in the plasma membrane, perinuclear membrane, total nuclear chromatin and distinct chromatin components of human breast cancer SK-BR-3 cells during apoptosis induced in vitro by the $\mathrm{Ca}^{2+}$ ionophore calcimycin. This fractal method should document the feasibility of using morphoultrastructural changes to assess the early phases of apoptosis that are not determinable by conventional cellular markers.

\section{Materials and methods}

\subsection{Reagents}

IMDM medium and fetal calf serum (FCS) were obtained from Seromed (Oxoid, Basel, Switzerland). DME/F-12 w/o phenol red was obtained from Sigma (Buchs, Switzerland). A23187 (Calcimycin) was purchased from Calbiochem (Juro supply AG, Lucerne, Switzerland). Annexin-V-FITC was purchased from Nexins Research B.V. (Hoeven, The Netherlands). Terminal deoxynucleotidyl transferase (TdT) and fluoroscein-11-dUTP were purchased from Amersham (Dübendorf, Switzerland). All other chemical and reagents of the finest grade of purity were purchased from Sigma and Fluka (Buchs, Switzerland), and organic solvents were purchased from Merck AG (Dietikon, Switzerland).

\subsection{Cell cultures}

Estrogen-insensitive SK-BR-3 human mammary cancer cells were cultured in IMDM supplemented with $2 \mathrm{mM}$ L-glutamine, $10 \%$ heat-inactivated FCS and $10 \mu \mathrm{g} / \mathrm{ml}$ gentamicin at $37^{\circ} \mathrm{C}$ in a humid $5 \% \mathrm{CO}_{2}$ atmosphere. Prior to the experiments, cells were cultured for $48 \mathrm{~h}$ at $10^{5}$ cells $/ \mathrm{ml}\left(2 \times 10^{4}\right.$ cells $\left./ \mathrm{cm}^{2}\right)$ in DME/F-12 medium without phenol red and supplemented with $5 \%$ heat-inactivated FCS. The medium was removed and the cells rinsed with DME/F-12. They were then incubated in DME/F-12 supplemented with 5\% heat-inactivated FCS containing $1 \mu \mathrm{M}$ A23187 in DMSO, while control cells were grown in medium plus an equivalent final concentration of DMSO $(0.1 \%)$. Treated and control cells were harvested by trypsinisation, rinsed and viability assessed by trypan blue exclusion and counted in a Neubauer chamber.

\subsection{Cell cycle analysis}

Cells $\left(10^{6}\right)$ were incubated at room temperature for $30 \mathrm{~min}$ in hypotonic $0.1 \%$ sodium citrate containing RNase (5 U/ml), 0.1\%, Triton X-100 and $50 \mu \mathrm{g} / \mathrm{ml}$ Propidium Iodide (PI) [22]. The percentages of cells in each phase of the cell cycle were measured by flow cytometric analysis on a FACScan (Becton \& Dickinson, Basel, Switzerland) equipped with CELLQuest software for acquisition and ModFit LT 2.0 (Verity Software House, Topsham, USA) for the evaluation of cell cycle on a fluorescence- 2 channel/area (FL-2A). Multiplets were discriminated by gating the events on a linear plot FL-2A versus fluorescence-2/width (FL-2W). Nuclei from human peripheral blood lymphocytes were used as an internal DNA standard. The subdiploid $\mathrm{G}_{0} / \mathrm{G}_{1}$ area was determined by measuring cellular events on a log histogram on PI fluorescence channel 2 (FL-2H) according to the method of Nicoletti et al. [23].

\subsection{Characterization of apoptotic cells}

\subsubsection{Membrane permeability assay}

The change in the permeability of the plasma membrane to PI was used to differentiate living from apoptotic and dead cells [22,24]. $5 \times 10^{5}$ SK-BR-3 cells were washed in $0.9 \% \mathrm{NaCl}$ ( $\mathrm{pH} 7.4)$, suspended in $5 \mu \mathrm{g} / \mathrm{ml} \mathrm{PI}$ in $0.9 \% \mathrm{NaCl}$, incubated for $7 \mathrm{~min}$ in the dark at RT, centrifuged and suspended in $0.9 \%$ $\mathrm{NaCl}$. PI uptake was analysed in a FACScan (Becton \& Dickinson, Basel, Switzerland) equipped with a CELLQuest software. The populations of living, apoptotic and dead cells were displayed in a two-parameter dot plot, i.e., PI fluorescence (FL-2H) versus cell dimension (FSC).

\subsubsection{Annexin-V labelling}

Annexin- $\mathrm{V}$ is an adhesion molecule that binds tightly to the phosphatidylserine on the outer leaflet of plasma membrane in the presence of $\mathrm{Ca}^{2+} .2 \times 10^{5}$ SK-BR-3 cells were washed with cold $0.9 \% \mathrm{NaCl}$ and incubated for $15 \mathrm{~min}$ at room temperature with $\mathrm{Ca}^{2+}$ binding buffer containing FITC-annexin-V (diluted 10-fold) and $1 \mu \mathrm{g} / \mathrm{ml}$ PI [25]. The stained cells were analysed for FITC-annexin-V in the fluorescence channel 1 (FL-1H) and for PI in the FL-2H channel with a FACScan (Becton \& Dickinson, Basel, Switzerland) equipped with CELLQuest software. 


\subsubsection{Terminal deoxynucleotidyl transferase-mediated dUTP nick end labelling assay (TUNEL)}

DNA strand breaks were labelled at $3^{\prime}-\mathrm{OH}$ ends with fluoroscein-deoxynucleotid (dUTP) by exogenous terminal deoxynucleotidyl transferase (TdT) according to a slightly modified version of a published method [26]. SK-BR-3 cells, untreated or treated with calcymicin were fixed in $0.5 \%$ formaldehyde in phosphate-buffered saline PBS (pH 7.4) for $20 \mathrm{~min}$ at room temperature, rinsed with PBS and postfixed with $70 \% \mathrm{EtOH}$ for $24 \mathrm{~h}$ at $-20^{\circ} \mathrm{C}$. Following fixation, the cells were rinsed twice with PBS containing $0.5 \%$ BSA and $0.1 \%$ sodium azide. Cells $\left(10^{6}\right)$ were resuspended in $50 \mu \mathrm{l}$ of a solution containing $100 \mathrm{mM}$ sodium cacodilate $(\mathrm{pH} 7.2), 2 \mathrm{mM} \mathrm{CoCl} 2,0.5 \mathrm{mM}$ mercaptoethanol, 0.5 nmoles FITC-labelled dUTP, 10 units of $\mathrm{TdT}$ and incubated in the dark for $30 \mathrm{~min}$ at $37^{\circ} \mathrm{C}$. Finally, the cells were rinsed twice with $0.1 \%$ Triton $\mathrm{X}$ 100 in PBS and then resuspended in PBS. Data were collected by a FACScan cytometer with an argon standard laser and a band-pass filter for FL1-H. Data analysis was performed with CELLQuest software. A control was carried up by omitting TdT.

\subsubsection{Enzyme activities}

The cell suspensions were sonicated ( 3 times of 30 seconds, $50 \%$ intensity at 0.5 cycles) in ice-cold $\mathrm{NaCl}$ $0.9 \% \mathrm{pH} 7.4$ and the enzyme assays were optimized for time, $\mathrm{pH}$, protein and substrate concentration.

$\gamma$-Glutamyltransferase ( $\gamma$-GT; EC 2.3.2.2) was assayed by incubating homogenates of cell suspension (50 $\mu \mathrm{g}$ protein) in $1 \mathrm{ml}$ of a reaction mixture containing $20 \mathrm{mM}$ Tris- $\mathrm{HCl}$ buffer $\mathrm{pH} 8.0,60 \mathrm{mM}$ glycylglycine, $300 \mathrm{mM} \mathrm{NaCl}$ and $2.5 \mathrm{mM} \gamma$-glutamylp-nitroanilide [22]. The reaction was terminated by adding $2 \mathrm{ml} 1.5 \mathrm{~N}$ acetic acid. The mixture was cleared by centrifuging $\left(800 \mathrm{~g}, 20 \mathrm{~min}\right.$ at $\left.4^{\circ} \mathrm{C}\right)$ and the absorbance of the p-nitroaniline in the supernatant was measured at $410 \mathrm{~nm}$ using a Beckman DU-65 spectrophotometer. The enzyme activity was expressed in $\mathrm{nmol} / \mathrm{min} / \mathrm{mg}$ protein.

Acidic sphingomyelinase (E.C 3.1.4.12; aSmase) was measured on total cell homogenates using a slightly modified version of the Klar's method [27]. The assay mixture containing $5 \mathrm{nmol} \mathrm{N}$-(1-pyrenedecanoyl)sphyngosylphosphocholine (P10-SPM) solubilized in ethanol, $0.2 \mathrm{mg}$ reduced Triton X-100, $0.5 \mathrm{M}$ sodium acetate buffer $(\mathrm{pH} 4.5), 50 \mu \mathrm{g}$ proteins in a final volume of $200 \mu \mathrm{l}$, was incubated in the dark for $2 \mathrm{~h}$ at $37^{\circ} \mathrm{C}$. The reaction was terminated by adding $1.5 \mathrm{ml}$ heptane, $0.45 \mathrm{ml}$ isopropyl alcohol and
$0.25 \mathrm{ml}$ water. After thoroughly mixing and centrifuging $(1500 \mathrm{~g}, 10 \mathrm{~min})$, the upper heptane-rich phase was transferred to a second test tube and back-washed with $0.35 \mathrm{ml}$ water. The fluorescence intensity of the upper heptane phase was determined at the excitation and emission wavelenghts of $344 \mathrm{~nm}$ and $374 \mathrm{~nm}$ respectively, using a Perkin Elmer LS-3B spectrofluorimeter. The amount of P10-ceramide released was deduced by reference to a standard curve plotted for known concentrations of fluorescent 10-(1-pyrene) decanoic acid (P10). Aliquots of the P10 standard in chloroform/methanol were evaporated under nitrogen and the residue dispersed with $1.5 \mathrm{ml}$ heptane, $0.45 \mathrm{ml}$ isopropyl alcohol and $0.45 \mathrm{ml}$ water. After vortexing, centrifuging and back-washing, the fluorescence ot the P10-containing heptane-rich phase was determined at the excitation and emission wavelenghts of $344 \mathrm{~nm}$ and $374 \mathrm{~nm}$, respectively. The enzyme activity was expressed in $\mathrm{nmol} / \mathrm{h} / \mathrm{mg}$ protein.

\subsection{Transmission electron microscopy}

Cells $\left(1-5 \times 10^{6}\right)$ were fixed for $2 \mathrm{~h}$ at $4^{\circ} \mathrm{C}$ in $30 \mathrm{~g} / 1$ glutaraldehyde in $70 \mathrm{mg} / \mathrm{l}$ calcium chloride and $0.1 \mathrm{M}$ sodium cacodylate, $\mathrm{pH} 7.4$, washed, and postfixed for $1 \mathrm{~h}$ at room temperature with a $2 \mathrm{~g} / 100 \mathrm{ml}$ osmium tetraoxide in $0.1 \mathrm{M}$ sodium cacodylate, adjusted to 340 mosm with $\mathrm{NaCl}$ to reduce artefacts. They were dehydrated in an ethanol series (70-100\%) and propylene oxide and embedded in Epon. Thin sections (interference color-grey/silver) were cut with an LKB 2128 microtome, mounted on 200-mesh grids coated with a formwar film and stained with $5 \mathrm{~g} / 100 \mathrm{ml}$ uranyl acetate for $5 \mathrm{~min}$ and with lead citrate for $5 \mathrm{~min}$. Photomicrographs were taken on plastic plates (Kodak EM film 4489) with a Philips 400-ET microscope at a magnification of $4600 \times$, which showed a single cell [10].

\subsection{Segmentation of cell components}

Electron microscopy (EM) negatives of SK-BR-3 cells, untreated or treated with A23187, were printed (Ilford, paper type 3) at a final magnification of $10580 \times$, scanned using a frame of $2007 \times 2007$ pixels with an Apple OneScanner (300 dpi/8 bit depth, 256 gray levels) and stored as TIFF files on a Macintosh $8100 / 80$ running Photoshop 2.5. Contour profiles of the plasma membrane were segmented by automatic thresholding of cell borders after interactive removal of the external impurities and debris from around to the cell. Outlines of the perinuclear membranes were 
traced manually using an A5 Wakom graphics tablet and segmented by a custom-written macro for the NIH Image 1.59 program (developed at the U.S. National Institute of Health and available from the Internet at http.//rsb.info.nih.gov./nih-image/). Three intranuclear regions of interest $(\mathrm{ROI})$, defined at $128 \times 128$ pixels, excluding nucleolar domains and nuclear membrane portions, were randomly systematic selected from a single nucleus and used to determine the fractal texture. An another series of experiments was devised to determine the fractal dimension of distinct chromatin species, which were segmented by thresholding the nuclear area [28] into chromatin regions and their contour profiles [29]. The reliability of the histogram-based grey level thresholding approach had previously been assessed on nuclear ROIs identified as above using an NIH Image 1.61 release on a G4 Macintosh computer running MAC OS 9. Grey level values established from ROIs images which had been smooth filtered and analyzed by an SPSS 6.1 program were found to fit well into two Gaussian distributions [30]. The optimal grey level threshold was set at the intersection point between these two distributions, and then used to segment ROI images into two grey level domains, namely one domain situated below the threshold and pertaining to the euchromatin space, and another domain above it, pertaining to the heterochromatin space. The grey level threshold (average) established for nuclear ROIs was used to segment the whole nucleus of breast cancer cells, after interactive removal of nucleoli, which would have interfered with the estimation of the fractal dimension of nuclear chromatins.

\subsection{Fractal dimension analysis}

The fractal parameters of the selected cell components were determined from digital pictures using the Fanal ++ package [31]. This includes subroutines for box-counting, data fitting and visualization and the power law application procedure for evaluating the fractal dimension [FD]. Nuclear chromatin and chromatin-containing ROIs were analyzed for FD by two methods. Firstly, the slice density approach, in which grey level histograms of ROIs were sliced at 20 grey level intervals across the entire grey level domain. This yielded a Gaussian distribution of FD values, with a maximum corresponding to a grey level interval of 90-130. The precise value of each ROI was determined by the experimental conditions and EM pictures. The second method was a cumulative approach in which the FD distribution was obtained by summing progressive grey level interval values; this tended towards an asymptotic saturated region (plateau), and yielded an FD within the range established by the first method. The first method was considered to be more reliable for establishing the optimal grey level value and was therefore used to measure the FD of interchromatin in treated and untreated nuclei. The CV of the mean fractal dimension for nuclear chromatin was less than $5 \%$, indicating that the ROIs selected were representative of the whole nuclei. Finally, the box-counting method was also applied to entire nuclei to determine the fractal dimension FD of grey level threshold-segmented images of perinuclear membrane outlines and of intranuclear chromatin components, namely total heterochromatin (HC), nuclear membrane-bound heterochromatin (NMBHC), scattered heterochromatin (SHC) and inter-euchromatin (IC). The FANAL + + program [31] was run on a workstation equipped with Linux S.U.S.E 6.2.

\subsection{Statistics}

Data were analyzed by $T$-test and by the MannWhitney $U$-test (two-tail $P$ values) in the SPSS software.

\section{Results}

\subsection{Cell markers of apoptosis}

Apoptosis was induced by $1 \mu \mathrm{M}$ calcimycin (A23187), a potent $\mathrm{Ca}^{2+}$ ionophore that arrests the cell cycle in the $G_{0} / G_{1}$ phase ${ }^{1}$ (data not shown). The active phase of apoptosis in SK-BR-3 cells detected as annexin- $\mathrm{V}$ positive cells occurred only after 3 days in culture, whereas cells with intermediate permeability to PI and a sub- $\mathrm{G}_{0} / \mathrm{G}_{1}$ peak or TUNEL positive cells with DNA fragmentation, which are prone to apoptosis, were detected after 2 days in culture. The number of cells expressing these cell markers increased until the completion of apoptosis after five days of treatment (Table 1). Calcimycin had opposing effects on two key enzymes know to be involved in the apoptosis of lymphoid and other cells. The activity of the plasma membrane $\gamma$-glutamyltransferase was reduced by $15 \%$ and $25 \%$ after $24 \mathrm{~h}$ and $48 \mathrm{~h}$ of treatment, respectively, and remained unaffected as the apoptotic process progressed, whereas the activity of the acidic sph-

\footnotetext{
${ }^{1}$ C. Casteli, PhD thesis, 2001.
} 
Table 1

Time-course expression of membrane and nuclear apoptotic markers in SKBR-3 cells, untreated and treated with $1 \mu \mathrm{M}$ A23187 Calcimycin

\begin{tabular}{cccccc}
\hline Hours & \multicolumn{3}{c}{ Plasma membrane markers } \\
\cline { 2 - 3 } \cline { 2 - 3 } & \multicolumn{2}{c}{ PI permeability (\%) } & \multicolumn{2}{c}{ Annexin-V (\%) } \\
\cline { 2 - 3 } \cline { 5 - 6 } & untreated cells & treated cells & & untreated cells & treated cells \\
\hline 0 & $8.4 \pm 2.4$ & $8.4 \pm 2.4$ & & $4.1 \pm 1.8$ & $4.1 \pm 1.8$ \\
24 & $13.7 \pm 9.2$ & $9.1 \pm 0.8$ & & $7.3 \pm 0.3$ & $8.6 \pm 6.6$ \\
48 & $10.3 \pm 0.6$ & $27.0 \pm 4.3^{*}$ & & $5.3 \pm 3.2$ & $8.5 \pm 6.0$ \\
72 & $6.5 \pm 1.0$ & $52.7 \pm 13.3^{* *}$ & & $5.2 \pm 4.6$ & $27.9 \pm 9.1^{* *}$ \\
96 & $10.0 \pm 5.2$ & $84.8 \pm 3.2^{* *}$ & & $5.7 \pm 0.6$ & $60.1 \pm 7.2^{* *}$ \\
\hline
\end{tabular}

\begin{tabular}{cccccc}
\hline Hours & \multicolumn{3}{c}{ Nuclear markers } \\
\cline { 2 - 3 } & \multicolumn{2}{c}{ TUNEL $(\%)$} & & \multicolumn{2}{c}{ Sub $\mathrm{G}_{0} / \mathrm{G}_{1}$ peak $(\%)$} \\
\cline { 2 - 3 } \cline { 5 - 6 } & untreated cells & treated cells & & untreated cells & treated cells \\
\hline 0 & $2.6 \pm 0.6$ & $2.6 \pm 0.6$ & & $5.1 \pm 1.8$ & $5.1 \pm 1.8$ \\
24 & $2.8 \pm 0.9$ & $10.4 \pm 2.1$ & & $3.2 \pm 0.4$ & $4.4 \pm 1.1$ \\
48 & $2.1 \pm 0.5$ & $22.7 \pm 3.1^{* *}$ & & $5.7 \pm 0.6$ & $15.4 \pm 6.6^{*}$ \\
72 & $2.2 \pm 1.3$ & $57.1 \pm 6.4^{* *}$ & & $3.8 \pm 0.1$ & $49.7 \pm 7.2^{* *}$ \\
96 & $3.4 \pm 1.0$ & $58.1 \pm 8.3^{* *}$ & & $7.5 \pm 3.0$ & $75.3 \pm 2.7^{* *}$ \\
\hline
\end{tabular}

Results (\%) are means \pm one SD of three separate experiments.

*; ** Significant different at $p<0.01$ and 0.001 , respectively, between untreated and treated cells.
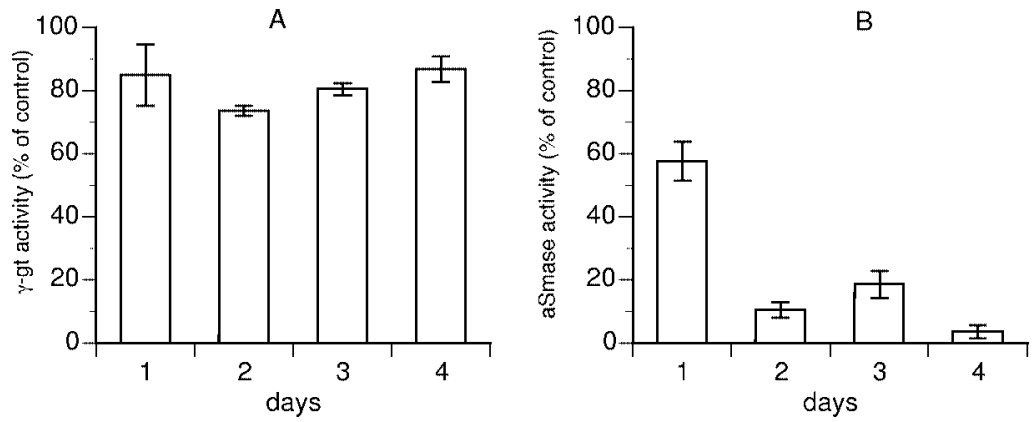

Fig. 1. A: Time-course of membrane $\gamma$-glutamyltransferase activity during apoptosis induced by $1 \mu \mathrm{M}$ calcimycin. B: Time-course of acidic sphingomyelinase activity during apoptosis induced by $1 \mu \mathrm{M}$ calcimycin. Results $(\%)$ are means \pm one SD of three separate experiments. The absolute specific activity of the $\gamma$-glutamyltransferase and acidic sphingomyelinase in untreated SK-BR-3 cells (24 h) is $24.1 \mathrm{nmol} / \mathrm{min} / \mathrm{mg}$ and $2.4 \mathrm{nmol} / \mathrm{h} / \mathrm{mg}$, respectively.

ingomyelinase had already been dramatically reduced $(40 \%)$ after one day of treatment, and was almost completely inhibited by the time the apoptotic process had been completed (Fig. 1 A,B).

\subsection{Ultrastructural features of apoptosis}

Quantitative assessment of the ultrastructural changes occurring in plasma and perinuclear membranes, which was not possible by means of subjective visual inspection, revealed that SK-BR-3 cells had entered the initial phases of apoptosis after being incubated with
$1 \mu \mathrm{M}$ calcimycin for $24 \mathrm{~h}$ (Fig. 2). In fact, it was found that the plasma membrane outline of the treated cells had a lower median FD (1.119) than that of the untreated cells (1.143) (Table 2). Morpho-ultrastructural data conflicted with the data reported in Table 1, which indicate that conventional apoptotic markers had not been affected by calcimycin after $24 \mathrm{~h}$ of treatment, even thought the early phases of apoptosis had been activated. A further sign was the low level of sub- $\mathrm{G}_{0} / \mathrm{G}_{1}$ peak observed in SK-BR-3 cells exposed to calcimycin for $24 \mathrm{~h}$. This was similar to that measured in control cells (Table 1). The difference in the morpholog- 


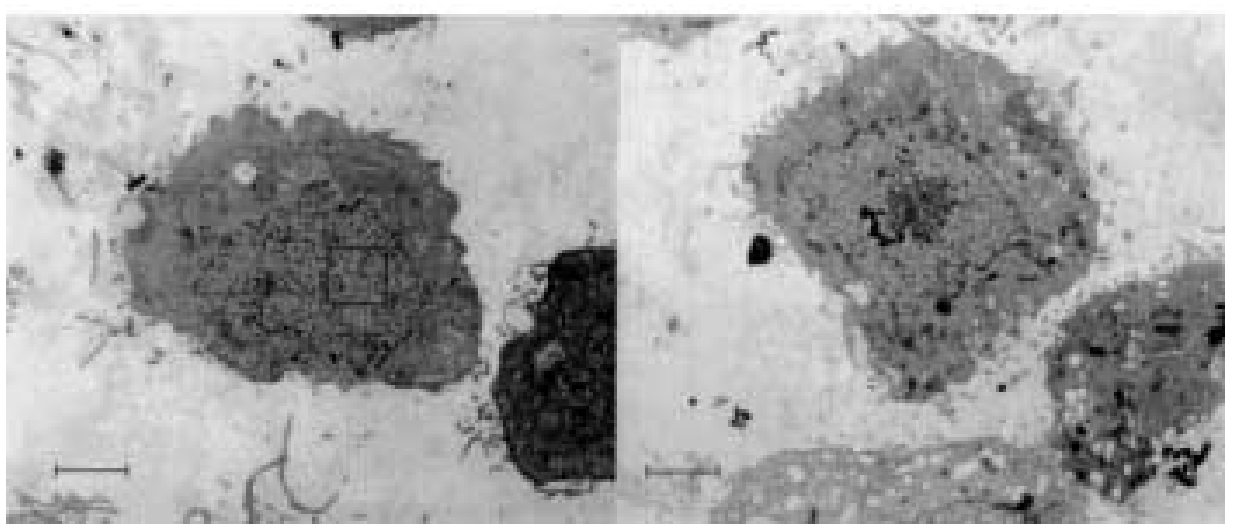

Fig. 2. EM view of SK-BR-3 cells, untreated (A) and treated with $1 \mu \mathrm{M}$ A23187 (B) for 24 h. $\square$ : region of interest ROI. Magnification $\times 4600$. Bar: $1 \mathrm{~cm}=2.17 \mu \mathrm{m}$.

Table 2

Fractal dimension (FD) of plasma and nuclear membrane outlines in SK-BR-3 cells, untreated (control) and treated with $1 \mu \mathrm{M}$ calcimycin for $24 \mathrm{~h}$. Results are median values \pm standard error on the median. Ranges of values are in the lower row. No significant difference between untreated and treated cells. $n$ : number of examined cells

\begin{tabular}{lcc}
\hline & \multicolumn{2}{c}{ Fractal Dimension $(\mathrm{FD})$} \\
\cline { 2 - 3 } & untreated cells & treated cells \\
& $(n=14)$ & $(n=15)$ \\
\hline FD plasma membrane & $1.143 \pm 0.013$ & $1.119 \pm 0.012$ \\
& $1.066-1.169$ & $1.059-1.179$ \\
FD nuclear membrane & $1.027 \pm 0.005$ & $1.012 \pm 0.008$ \\
& $0.995-1.046$ & $0.996-1.103$ \\
\hline
\end{tabular}

ical complexity of the perinuclear membranes in control (median FD $=1.027 \pm 0.005)$ and treated $(1.012$ $\pm 0.008)$ cells confirmed the tendency towards a loss of morphological traits even during early apoptosis (Table 2). Segmented images of isolated nuclei obtained by histograms of 20 grey level slices were submitted to the FD analysis. The maximum FD corresponded to a grey level interval identifying a domain associated with the interchromatin space on nuclear EM pictures. The median FD of the interchromatin space (euchromatin) in the nuclei of treated cells was the same as the FD of the nucleolus-free interchromatin space, but was significantly lower than the median FD in the corresponding domains of nuclei from control cells (Table 3). The difference in FD between the nuclear ROIs of control and treated cells was even more pronounced, although the median FD values (control: 1.591; treated: 1.547; $p<0.0001)$ were somewhat lower than those for nuclear interchromatin (Table 3). The more progressive the apoptotic process, the greater the reduction
Table 3

Fractal dimension (FD) of the interchromatin space (IC) and of intranuclear chromatin regions of interest (ROIs) segmented by grey level slice density approach. Cell treatment: $1 \mu \mathrm{M}$ calcimycin for 24 $\mathrm{h}$. Results are median values \pm standard error on the median. Ranges of values are in the lower row. $n$ : number of examined images. $p$ : significance evaluated by the Mann-Whitney test

\begin{tabular}{cccc}
\hline & \multicolumn{3}{c}{ Fractal Dimension (FD) } \\
\cline { 2 - 4 } & untreated cells & treated cells & $p$ \\
\hline IC & $1.714 \pm 0.0087$ & $1.679 \pm 0.0152$ & 0.0073 \\
& $1.652-1.745$ & $1.543-1.727$ & \\
& $(n=14)$ & $(n=14)$ & \\
IC w/o nucleolus & $1.716 \pm 0.0097$ & $1.677 \pm 0.0152$ & 0.0049 \\
& $1.648-1.745$ & $1.542-1.727$ & \\
& $(n=14)$ & $(n=15)$ & \\
ROIs & $1.591 \pm 0.0071$ & $1.547 \pm 0.0078$ & $<0.0001$ \\
& $1.473-1.645$ & $1.446-1.650$ & \\
& $(n=42)$ & $(n=44)$ & \\
\hline
\end{tabular}

in FD. No significant changes in the ultrastructure of cell membrane or nuclear components ${ }^{2}$ were induced if the exposure to the ionophore lasted less than $24 \mathrm{~h}$ (data not shown). The morphofractal characterization of the entire nucleus revealed that in SK-BR-3 cells exposed for calcimycin for $24 \mathrm{~h}$ and in untreated SKBR-3 cells, distinct nuclear components segmented by grey level thresholding had peculiar FD values (Table 4). The highest FD value identified the interchromatin space (IC), whereas the lowest FD was measured on the membrane-bound heterochromatin outline of both treated and untreated SK-BR-3 cells. It is noteworthy that the membrane-bound heterochromatin domains (NMBHC space and outline) of treated cells

\footnotetext{
${ }^{2}$ C. Castelli, PhD thesis, 2001.
} 
Table 4

Fractal dimension (FD) of nuclear components segmented by grey level threshold method. IC: inter(eu)chromatin; HC: total nuclear heterochromatin; NMBHC: nuclear membrane-bound heterochromatin; SCH: nuclear scattered heterochromatin. Cell treatment: $1 \mu \mathrm{M}$ calcimycin for $24 \mathrm{~h}$. Results are medians \pm standard error on the median. No significant difference between untreated and treated cells. $n$ : number of examined nuclei

\begin{tabular}{lcc}
\hline Nuclear components & \multicolumn{2}{c}{ Fractal Dimension (FD) } \\
\cline { 2 - 3 } & $\begin{array}{c}\text { untreated cells } \\
(n=14)\end{array}$ & $\begin{array}{c}\text { treated cells } \\
(n=15)\end{array}$ \\
\hline nuclear membrane outline & $1.051 \pm 0.0047$ & $1.039 \pm 0.0087$ \\
NMBHC space & $1.374 \pm 0.0315$ & $1.393 \pm 0.0489$ \\
NMBHC outline & $1.319 \pm 0.0288$ & $1.345 \pm 0.0248$ \\
SHC space & $1.499 \pm 0.0328$ & $1.482 \pm 0.0328$ \\
SHC outline & $1.472 \pm 0.0305$ & $1.454 \pm 0.0341$ \\
IC space & $1.833 \pm 0.0070$ & $1.808 \pm 0.0228$ \\
IC outline & $1.619 \pm 0.0318$ & $1.605 \pm 0.0325$ \\
HC space & $1.595 \pm 0.0288$ & $1.578 \pm 0.0328$ \\
HC outline & $1.565 \pm 0.0275$ & $1.552 \pm 0.0569$ \\
\hline
\end{tabular}

A
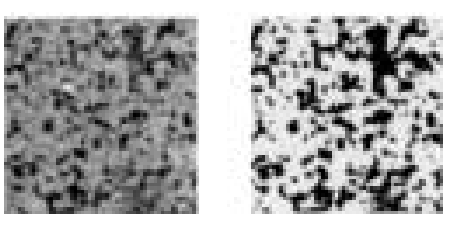

Fig. 3. A: EM view of ROI (magnification $\times 10580)$ identified on nuclei of untreated SK-BR-3 cells. B: view of nuclear ROI from Fig. 3A segmented by grey level threshold method. Black regions correspond to scattered heterochromatin (SHC) and white regions to inter(eu)chromatin (IC). ROI dimensions are arbitrary.

were the only nuclear components with an FD that was higher than that of control cells. However, there was no significant difference in the FD for any nuclear components between untreated cells and those treated for $24 \mathrm{~h}$ (Table 4).

\section{Discussion}

We have developed a new morphometric strategy that uses grey level thresholding segmentation and fractal geometry to identify and characterize the onset and early phases of apoptosis induced by calcimycin in estrogen-insensitive SK-BR-3 human breast cancer cells. This method was found to provide a reliable quantitative analysis of very fine ultrastructural changes of the cell membrane and nuclear components, and to be much more effective than the cytofluorimet- ric assays of cellular markers, which can only be detected during the active phases of apoptosis. Our morphometric findings revealed a general trend towards a loss of complexity, in terms of fractal dimension, of the ultrastructural features of the plasma membrane, perinuclear membrane, inter(eu)chromatin space, scattered heterochromatin and total heterochromatin, with the exception of the perinuclear membrane-bound heterochromatin. The changes detected indicate that the reorganization of cell components, including chromatin, begin in the early phases of apoptosis induced in vitro by $\mathrm{Ca}^{2+}$ ionophore, well before membrane phosphatidylserine (PS) exposure, membrane permeability to PI, DNA fragmentation (TUNEL and subdiploid $\mathrm{G}_{0} / \mathrm{G}_{1}$ peak), chromatin condensation (compactness) [32], marginalization or the formation of apoptotic bodies. The annexin- $\mathrm{V}$ assay detected membrane phosphatidylserine after SK-BR-3 cells have been incubated with $1 \mu \mathrm{M}$ calcimycin for $72 \mathrm{~h}$, revealing that PS exposure did not occur at the beginning of the apoptotic process, in line with data reported for other non lymphoid cell systems [33]. The ultrastructural changes of the early apoptotic process were supported by enzyme activity changes: the $\gamma$-GT, an ectoenzyme contributing to the synthesis of the intracellular antioxidant glutathione (GSH) and which is involved in the apoptotic events of lymphoid cells [22, 34] was found most reduced after $48 \mathrm{~h}$ of treatment. Unexpectedly, a dramatic reduction in acidic sphingomyelinase was detected already after $24 \mathrm{~h}$ of treatment, which contrasted with the activation of this enzyme observed in lymphoid cell cultures, when apoptosis was induced through the APO/FAS and TNF pathways by apoptogens other than calcimycin [3537]. Apart from a different apoptotic signalling pathway, an other possible explanation of this difference could be that calcimycin may activate a $\mathrm{Ca}^{2+}$ dependent proteolytic pathway which degrades or inhibits the acidic sphingomyelinase [38]. The FD of the perinuclear membrane of estrogen-insensitive SK-BR-3 human breast cancer cells is lower than that of estrogensensitive MCF-7 human breast cancer cells. However, the FD of the perinuclear membrane of MCF7 cells is unchanged after a brief exposure to $1 \mathrm{nM}$ $17 \beta$-estradiol, a steroid hormone of cell proliferation [21], whereas it is reduced in apoptotic SK-BR3 cells treated with calcimycin. It has been recently reported [39] that the FD of the perinuclear membrane of invasive ductal breast carcinoma is slightly higher (1.1) than that of SK-BR-3 cells (1.03) reported in the present study. Methods based on grey 
level density discrimination have been used to measure the FD of chromatin texture of nuclei in normal and malignant cells [13,15-18,40,41]. Electron microscopy studies have recently documented the behaviour and the ultrastructural rearrangement of nuclear domains and ribonucleoprotein-containing structures during apoptosis of leukemic cells [42-44] and thymocytes [45]. Fractal morphometry and spatial grey level co-occurrence matrices statistics were carried out on electron microscopy images to characterize euchromatin and heterochromatin nuclear domains $[46,47]$. But, as far as we know, there have been no EM studies of the FD of non-lymphoid human cancer cells undergoing apoptosis. Our finding of a loss of morphological traits in calcimycin-induced apoptotic cells partially agrees with the data reported by the other authors, who have shown a significant reduction in the FD of intranuclear chromatin in lymphoid Jurkat cells in which apoptosis had been induced with APO/Fas [48].

\section{Acknowledgements}

This work was supported by grant 31-57626.99 from the Swiss National Science Foundation and grant FOR 450.94 from the Swiss Cancer League.

\section{References}

[1] A.H. Wyllie, J.F.R. Kerr and A.R. Currie, Cell death: the significance of apoptosis, Int. Rev. Cytol. 68 (1980), 251-306.

[2] J.F.R. Kerr, C.M. Winterforth and B.V. Harmon, Apoptosis. It's significants in cancer and cancer therapy, Cancer 73 (1994), 2013-2026

[3] G. Maino and I. Joris, Apoptosis, oncosis and necrosis, Am. J. Pathol. 146 (1995), 3-15.

[4] R.A. Schwartzman and J.A. Cidlowski, Apoptosis: the biochemistry and molecolar biology of programmed cell death, Endocrine Rev. 14 (1993), 133-151.

[5] G.A. Losa and R. Graber, Apoptotic cell death and the proliferative capacity of human breast cancer, Anal. Cell. Pathol. 16 (1998), 1-10.

[6] D.J.P. Ferguson and T.J. Anderson, Ultrastructural observation on cell death by apoptosis in the resting human breast, Virchows Arch. 393 (1981), 193-203.

[7] B.B. Mandelbrot, The Fractal Geometry of the Nature, Freeman, San Francisco, 1983.

[8] J. Dufer, M.-F. Poupon and S. Yatouji, Nuclear DNA content and chromatin pattern of rat rhabdomyosarcoma cell sublines with different metastatic potentials, Anal. Cell. Pathol. 20 (2000), 41-48.
[9] G.A. Losa and T.F. Nonnenmacher, Self-similarity and fractal irregularity in pathologic tissues, Modern Pathol. 9 (1996), 174-182.

[10] G.A. Losa, G. Baumann and T.F. Nonnenmacher, Fractal dimension of pericellular membranes in human lymphocytes and lymphoblastic leukemic cells, Path. Res. Pract. 188 (1992), 680-686.

[11] G. Baumann, A. Barth and T.F. Nonnenmacher, Measuring fractal dimension of cell contours: practical approaches and their limitations, in: Fractals in Biology and Medicine, Vol. 1, Birkhäuser-Verlag, Basel, 1994, pp. 182-189.

[12] T.F. Nonnenmacher, G. Baumann, A. Barth and G.A. Losa, Digital image analysis of self-similar cell profiles, J. Bio-Med. Comp. 37 (1994), 131-138.

[13] A.J. Einstein, W. Hai-Shan and J. Gil, Fractal characterization of nuclear texture in breast cytology: frequency and spatial domain approaches, in: Fractals in Biology and Medicine, Vol. 2, Birkäuser-Verlag, Basel, 1998, pp. 190-206.

[14] G. Landini and J.W. Rippin, Quantification of nuclear pleomorphism using asymptotic fractal model, Anal. Quant. Cytol. Histol. 18 (1996), 167-176.

[15] T. Irinopoulou, J.P. Rigaut and M.C. Benson, Toward objective prognostic grading of prostatic carcinoma using image analysis, Anal. Quant. Cytol. Hystol. 15 (1993), 341-414.

[16] C. MacAulay and B. Palcic, Fractal texture features based on optical density surface area. Use in image analysis of cervical cells, Anal. Quant. Cytol. Histol. 12 (1990), 394-398.

[17] B. Nielsen, F. Albregtsen and H.E. Danielsen, The use of fractal features from the periphery of cell nuclei as a classification tool, Anal. Cell. Pathol. 19 (1999), 21-37.

[18] A. Doudkine, C. MacAulay, N. Poulin and B. Palcic, Nuclear texture measurements in image cytometry, Pathologica 87 (1995), 286-299.

[19] S.S. Cross, Fractals in pathology, J. Pathol. 182 (1996), 1-8.

[20] G. Bianciardi, C. Miracco, M.M.D. Santi, A. Perrone, A. Bruni and P. Luzi, Fractal dimension of lymphocytic nuclear membrane in mycosis fungoides and chronic dermatitis, in: Fractals in Biology and Medicine, Vol. 2, Birkäuser-Verlag, Basel, 1998, pp. 231-237.

[21] G.A. Losa, R. Graber, G. Baumann and T.H. Nonnenmacher, Effects of steroid hormones on nuclear membrane and membrane-bound heterochromatin from breast cancer cells evaluated by fractal morphometry, Anal. Quant. Cytol. Histol. 21 (1999), 430-436.

[22] R. Graber and G.A. Losa, Changes in the activities of signal transduction and transport membrane enzymes in CEM lymphoblastoid cells by glucocorticoid-induced apoptosis, Anal. Cell. Pathol. 8 (1995), 159-176.

[23] I. Nicoletti, G. Migliorati, M.C. Pagliacci, F. Grignani and C. Riccardi, A rapid and simple method for measuring thymocyte apoptosis by propidium iodide staining and flow cytometry, J. Immunol. Methods 139 (1991), 271-279.

[24] M.G. Ormerod, M.K.L. Collins, G. Rodriguez-Tarduchy and D. Robertson, Apoptosis in interleukin-3-dependent haemopoietic cells, J. Immunol. Methods 153 (1992), 57-65.

[25] I. Vermes, C. Haanen, H. Steffens-Nakken and C. Reutelingsperger, A novel assay for apoptosis. Flow cytometric detection of phosphatidylserine expression on early apoptotic cells using fluoroscein labelled annexin V, J. Immunol. Methods 184 (1995), 39-51 
[26] W. Gorczyca, J. Gong and Z. Darzynkiewicz, Detection of DNA strand breaks in individual apoptotic cells by the in situ terminal deoxynucleotidyl transferase and nick translation assay, Cancer Res. 53 (1993), 1945-1951.

[27] R. Klar, T. Levade and S. Gatt, Synthesis of pyrenesulfonylamido-sphingomyelin and its use as substrate for determining sphingomyelinase activity and diagnosing Niemann-Pick disease, Clin. Chim. Acta 176 (1988), 259-268.

[28] J. Kittler and J. Illingworth, Minimum error thresholding, Pattern Recognition 19 (1986), 41-47.

[29] N.M. Maraldi, N. Zini, S. Santi, A. Ognibene, R. Rizzoli, G. Mazzotti and F.A. Manzoli, Cytochemistry of the functional domains of the nucleus in normal and in pathologic conditions, Eur. J. Histochem. 42 (1998), 41-53.

[30] C.A. Glasbey and G.W. Horgan, Image Analysis for the Biological Sciences, John Wiley \& Sons, Chichester, 1995.

[31] J.W. Dollinger, R. Metzler and T.F. Nonnenmacher, Biasymptotic fractals: Fractals between lower and upper bounds, J. Phys.: Math. Gen. 31 (1998), 3839-3847.

[32] F. Oberhammer, G. Fritsch, M. Schmied, M. Pavelka, D. Printz, T. Purchio, H. Lassmann and R. Schulte-Hermann, Condensation of the chromatin at the membrane of an apoptotic nucleus is not associated with activation of an endonuclease, J. Cellular Sciences 104 (1993), 317-326.

[33] R. Gatti, S. Belletti, G. Orlandini, O. Bussolati, V. Dall'Asta and G.C. Gazzola, Camparison of annexin-V and calcein-AM as early vital markers of apoptosis in adherent cells by confocal laser microscopy, J. Histochem. Cytochem. 46 (1998), 895-900.

[34] G.A. Losa and R. Graber, Spontaneous apoptosis, oxidative status and immunophenotype markers in blood lymphocytes of AIDS patients, Anal. Cell. Pathol. 21 (2000), 11-20.

[35] Y. Hannun, Functions of ceramide in coordinating cellular responses to stress, Science 274 (1996), 1855-1899.

[36] W.D. Jarvis, S. Grant and R.N. Kolesnick, Ceramide and the induction of Apoptosis, Clin. Cancer Res. 2 (1996), 1-6.

[37] M.G. Cifone, P. Roncaioli, R.D. Maria, G. Camarda, A. Santoni, G. Ruberti and R. Testi, Multiple pathways originate at the Fas/APO-1 (CD95) receptor: sequential involvement of phosphatidylcholine-specific phospholipase $\mathrm{C}$ and acidic sphingomyelinase in the propagation of the apoptotic signal, EMBO J. 14 (1995), 5859-5868.
[38] D.E. Johnson, Noncaspase proteases in apoptosis, Leukemia 14 (2000), 1695-1703.

[39] B. Wehn, G.V.D. Wouwer, A.V. Daele, P. Scheunders, D.V. Dick, E.V. Marck and W. Jakob, Automated breast tumor diagnosis and grading based on wavelet chromatin texture description, Cytometry 33 (1998), 32-40.

[40] F. Sepulcre, J. Grau and M. Garcia-Bonafé, Cell differentiation by studying the chromatin texture. A fractal approach, in: Fractals in Biology and Medicine, Vol. 2, Birkäuser-Verlag, Basel, 1998, pp. 226-230.

[41] B. Wehn, G.V.D. Wouwer, M. Koprowski, A.V. Daele, K. Dhaene, P. Scheunders, W. Jakob and E.V. Marck, Value of morphometry, texture analysis, densitometry, and histometry in the differential diagnosis and prognosis of malignant mesothelioma, J. Pathol. 189 (1999), 581-589.

[42] L. Stuppia, P. Gobbi, L. Zamai, M. Vitale and E. Falcieri, Morphometric and functional study of apoptotic cell chromatin, Cell Death Differ. 3 (1996), 397-405.

[43] E. Falcieri, L. Zamai, S. Santi, C. Cinti, P. Gobbi, D. Bosco, A. Cataldi, C. Betts and M. Vitale, The behaviour of nuclear domains in the course of apoptosis, Histochemistry 102 (1994), 221-231.

[44] E. Falcieri, P. Gobbi, L. Zamai and M. Vitale, Ultrastructural features of apoptosis, Scanning Microscopy 8 (1994), 653-666.

[45] M. Biggiogera, M.G. Bottone and C. Pellicciari, Nuclear ribonucleoprotein-containing structures undergo severe rearrangement during spontaneous thymocyte apoptosis. A morphological study by electron microscopy, Histochem. Cell Biol. 107 (1997), 331-336.

[46] F. Marinelli, R. Santoro and N.M. Maraldi, Fractal analysis of heterochromatin in nuclear domains in lymphocytes, in: Fractals in Biology and Medicine, Vol. 2, Birkäuser-Verlag, Basel, 1998, pp. 220-225.

[47] K.L. Chan, Quantitative characterization of electron micrograph image using fractal feature, IEEE Trans. Biomed. Eng. 42 (1995), 1033-1037.

[48] R. Santoro, F. Marinelli, G. Turchetti, N. Zini, K. Scotland, R. Falcieri and N.M. Maraldi, Fractal analysis of chromatin during apoptosis, in: Fractals in Biology and Medicine, Vol. 3, Birkäuser-Verlag, Basel, 2001, pp. 200-208. 


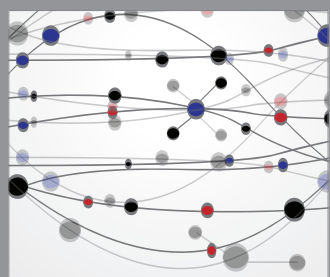

The Scientific World Journal
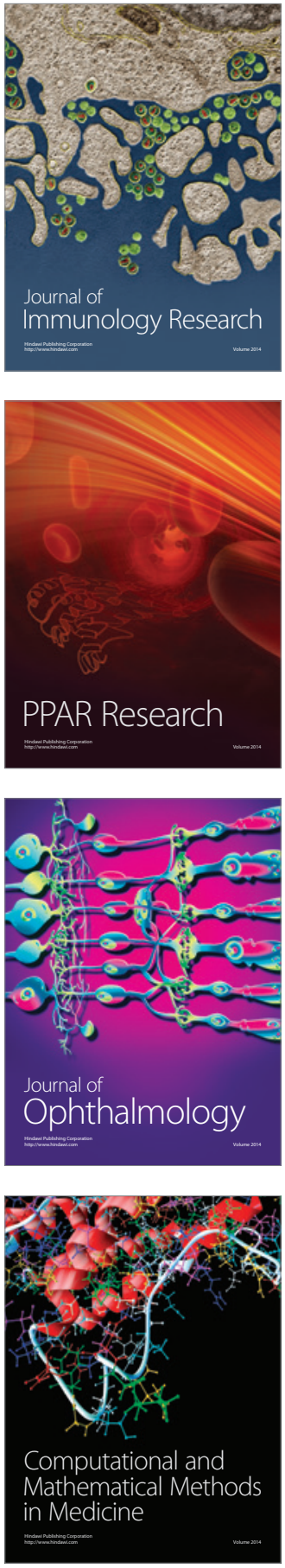

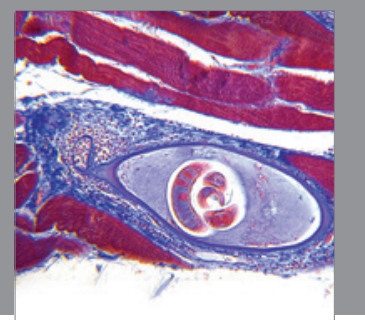

Gastroenterology

Research and Practice
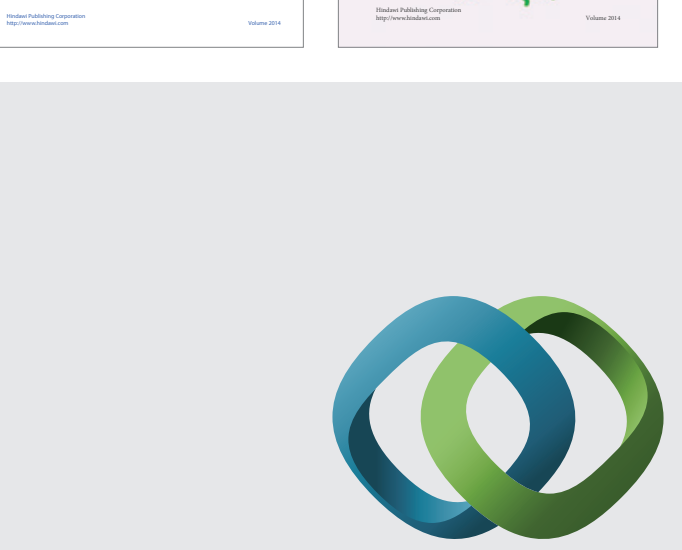

\section{Hindawi}

Submit your manuscripts at

http://www.hindawi.com
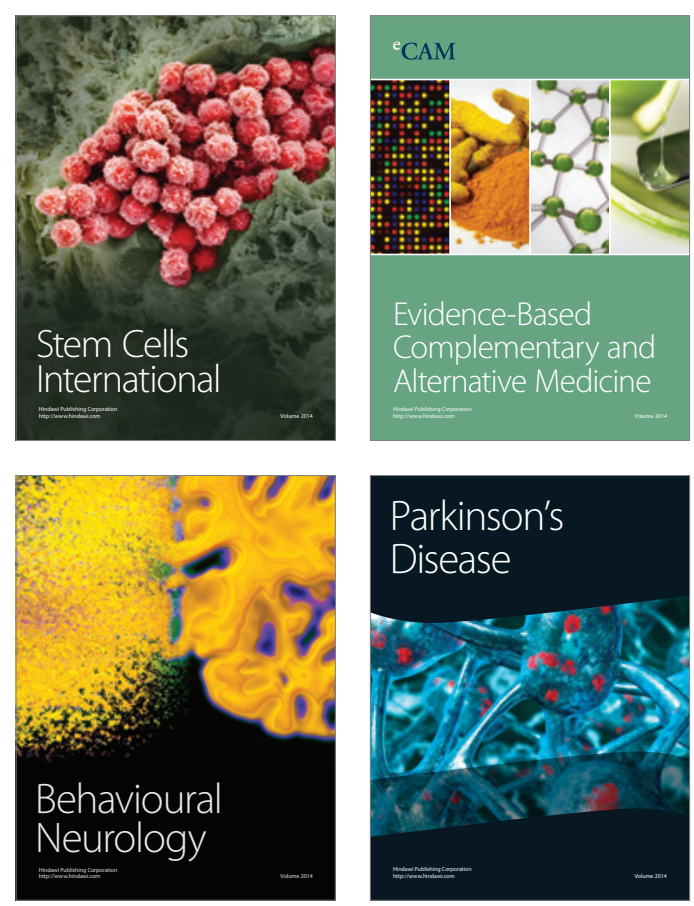

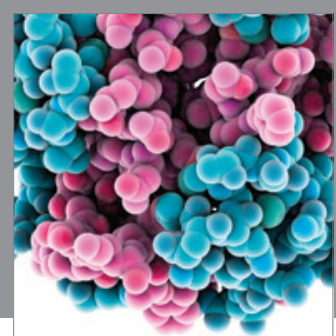

Journal of
Diabetes Research

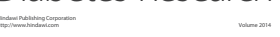

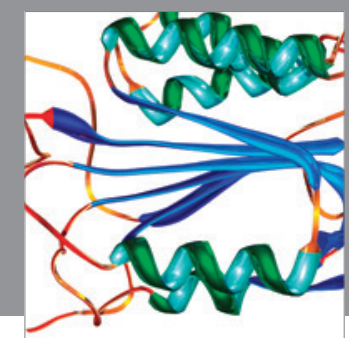

Disease Markers
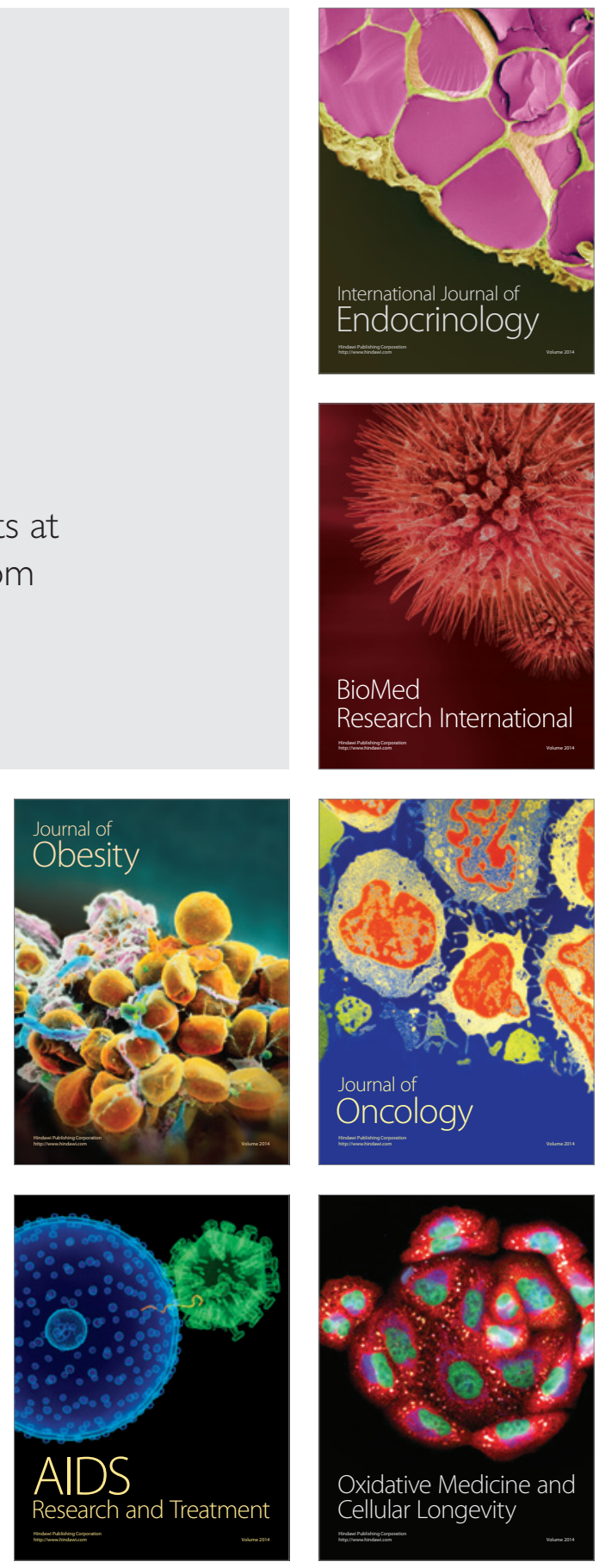